\title{
Marker-Assisted Evaluation of Two Powdery Mildew Resistance Candidate Genes in Korean Cucumber Inbred Lines
}

\author{
Mahdi Badri Anarjan ${ }^{1}$, Ikhyun Bae ${ }^{2}$ and Sanghyeob Lee ${ }^{1,3, * \mathbb{D}}$ \\ 1 Plant Genomics Laboratory, Department of Bio-Resource Engineering, College of Life Sciences, \\ Sejong University, Seoul 05006, Korea; st_m.badri@urmia.ac.ir \\ 2 Breeding Research Institute, DONGOH SEED, Icheon 17405, Korea; ihbae@dongoh.co.kr \\ 3 Plant Engineering Research Institute, Sejong University, Seoul 05006, Korea \\ * Correspondence: sanglee@sejong.ac.kr; Tel.: +82-2-3408-4375; Fax: +82-2-3408-4318
}

Citation: Badri Anarjan, M.; Bae, I.; Lee, S. Marker-Assisted Evaluation of Two Powdery Mildew Resistance Candidate Genes in Korean Cucumber Inbred Lines. Agronomy 2021, 11, 2191. https://doi.org/10.3390/ agronomy11112191

Academic Editors: Sara Sestili, Nadia Ficcadenti and Mehtap Yıldız

Received: 29 September 2021

Accepted: 26 October 2021

Published: 29 October 2021

Publisher's Note: MDPI stays neutral with regard to jurisdictional claims in published maps and institutional affiliations.

Copyright: (c) 2021 by the authors. Licensee MDPI, Basel, Switzerland. This article is an open access article distributed under the terms and conditions of the Creative Commons Attribution (CC BY) license (https:// creativecommons.org/licenses/by/ $4.0 /)$.

\begin{abstract}
Two genes, CsLRR-RPK2 (CsGy5G015660) and CsaMLO8 (Csa5G623470), have been considered as powdery mildew (PM) resistance genes in cucumbers. In this study, we evaluated the involvement of the alleles of these two genes in PM resistance in 100 commercial Korean cucumber inbred lines. To achieve this, we developed cleaved amplified polymorphic sequences (CAPS) and InDel markers from CsLRR-RPK2 and CsaMLO8. Genotyping analysis indicated that the CsLRR-RPK2-CAPS marker showed a stronger correlation with the PM-resistant phenotype, with an $84 \%$ consistency compared to the CsaMLO8-InDel marker. The use of the CsaMLO8-InDel marker showed a 70\% consistency between phenotype and genotype results. It was proposed that the CsLRRRPK2-CAPS marker successfully eliminated PM-susceptible inbred lines, since both genotype and phenotype results were $100 \%$ identical. Furthermore, the present study revealed that the introduction of one of these alleles is probably enough to confer PM resistance in cucumbers. However, seven PM-resistant inbred lines harbored either CsaMLO8 or CsLRR-RPK2 alleles, indicating that there is another PM-resistant resource(s) besides CsaMLO8- and CsLRR-RPK2-originated resistance in the commercial Korean inbred lines. Our results provide reliable evidence confirming two PM-resistant candidate genes for the detection of PM resistance resources in cucumber inbred lines.
\end{abstract}

Keywords: Cucumis sativus L.; Podosphaera xanthii; PM-resistance resource; MLO; LRR-RPK2

\section{Introduction}

The cucumber [Cucumis sativus L. $(2 \mathrm{n}=2 \mathrm{x}=14)$ ] is a member of the Cucurbitaceae family, which is the same botanical family as melons and squashes [1]. It is an economically important vegetable cultivated worldwide [2]. Powdery mildew (PM) is one of the most serious productivity and quality-loss-inducing diseases in cucumber-growing fields and greenhouses worldwide. Two pathogens, Podosphaera xanthii and Golovinomyces cichoracearum, have been recognized as the hard-to-control fungi that cause PM disease [3-10]. Among them, $P$. xanthii is predominant in most countries, including Korea [3-7,9-12]. To date, the application of protective fungicides has been considered a vital way to control $P$. xanthii. However, P. xanthii has become resistant to fungicides for many years [13-18]. In addition, many consumers have become focused on social issues, such as environmental protection and public health. Accordingly, the most efficient and environmentally friendly way to control the spread of $P$. xanthii is the breeding of PM-resistant cultivars [7].

It is necessary to understand the genetic and molecular mechanisms of PM resistance in the breeding of PM-resistant cucumber cultivars. Several efforts have been made to identify the PM resistance loci in cucumber. As a result of these efforts, six temperaturedependent QTLs (chromosomes 1, 5, 6, and 7) from PI 197088-1, five PM-resistance QTLs (PM1.1, PM1.2, PM2.1, PM2.2, and PM5.1) from S06, two QTLs (chromosome 5) from PI 250147, four QTLs ( $p m 5.1, p m 5.2, p m 5.3$, and pm6.1) from K8, six QTLs (pm1.1, pm1.2, pm3.1, pm4.1, pm5.1, and pm5.2) from WI 2757, nine QTLs (pm1.1, pm1.2, pm2.1, pm3.1, pm4.1, pm5.1, 
pm5.2, pm5.3, and pm6.1) from CS-PMR1, and four QTLs (pm1.1, pm2.1, pm5.1, and pm 6.1) from PI 197088 [1,6,19-23] have been identified. Although we have deep insight into the genetic inheritance of PM resistance, it is very difficult to directly use the information on PM-resistant QTLs to select the PM-resistant germplasm.

From a practical point of view, molecular markers for the selection of the PM-resistant germplasm from the above QTL regions should be developed. Several studies have reported candidate gene(s) that govern PM resistance in different cucumber germplasms. For example, $\mathrm{Xu}$ et al. [24] identified two genes (Csa1G064780 and Csa1G064790) encoding a putative cysteine-rich receptor-like kinase from the 41.1-kb region of the Jin5-508-derived SSSL0.7 line. Three possible candidate genes, Csa5G622800, Csa5G622830, and Csa5G623490 that encode, identified from Cucumis hystrix introgression lines, and a single recessive gene (Csa5G622830), which encodes GATA transcription factors, have been considered candidates for controlling PM resistance [25]. From PI 197088 and C. sativus cv. Anaxo, a single-recessive gene (CsaMLO8, Csa5G623470) is considered a strong candidate gene for PM-susceptibility $[16,17,26,27]$.

To date, CsaMLO8 is the only cucumber PM-resistant gene whose function has been identified. Our previous recent study identified CsGy5G015660, which encodes a putative leucine-rich repeat receptor-like serine/threonine kinase (CsLRR-RPK2), as a strong PMresistant candidate gene derived from a Korean inbred line [28]. In the current study, we applied PM-resistant molecular markers derived from two PM-resistant candidate genes (CsaMLO8 and CsLRR-RPK2) to 100 Korean inbred lines to evaluate the accuracy of marker-assisted selection. Furthermore, we attempted to understand the origin of PM resistance in Korean cucumber inbred lines.

\section{Materials and Methods}

\subsection{Plant Materials and Cultivation}

In the present study, we used 100 commercial Korean cucumber inbred lines, including sixty-two PM resistant lines. The $\mathrm{F}_{1}$ progenies were generated by crossing different PMsusceptible (GHDHW, HD, LC, CPA, RV, FPDN and MDSS) and PM-resistant parental lines (CA/794, 2K79, 64E2K9, 2JKJ, 249, 253XNH, K9AKJ, 64E3K9, 045911., KJK9, JCDS and 02789AGN). Detailed information is shown in Table 1. In this study, twelve different PM-resistant resources were used as PM-resistant donor plants (Table 1). Consecutive self-pollinations from these progenies were performed to obtain the $\mathrm{F}_{3}-\mathrm{F}_{9}$ generation and pure lines. The seeds used in this study were kindly supplied by DONGOH SEED (Ansung, Korea). All seeds used in this study were germinated indoors in the spring of 2020 and then transplanted to DONGOH SEED greenhouse. All plants were irrigated, fertilized, and treated with pesticides according to the standard cultivation protocol of DONGOH SEED.

Table 1. List of PM resistant and PM-susceptible lines used for making inbred lines.

\begin{tabular}{|c|c|c|}
\hline \multicolumn{2}{|c|}{ Crossing Combination } & \multirow{2}{*}{$\begin{array}{c}\text { Types of PM Resistance } \\
\text { Source }\end{array}$} \\
\hline Resistance Source & Susceptible Source & \\
\hline CA/794 (우) & GHDHW $\left(\sigma^{7}\right)$ & A \\
\hline 2K79 (ㅇ) & $\operatorname{HD}\left(\sigma^{7}\right)$ & B \\
\hline 64E2K9 (우) & $\operatorname{HD}\left(\sigma^{7}\right)$ & $\mathrm{C}$ \\
\hline 2JKJ (o) & $\operatorname{LC}\left(\sigma^{x}\right)$ & $\mathrm{D}$ \\
\hline $249\left(0^{7}\right)$ & LC (ㅇ) & $\mathrm{E}$ \\
\hline 253XNH $\left(\sigma^{7}\right)$ & CPA (우) & $\mathrm{F}$ \\
\hline K9AKJ (ㅇ) & CPA $\left(\sigma^{7}\right)$ & G \\
\hline 64E3K9 (우) & $R V\left(\sigma^{7}\right)$ & $\mathrm{H}$ \\
\hline 045911 (우) & $\mathrm{RV}\left(\sigma^{x}\right)$ & $\mathrm{I}$ \\
\hline KJK9 (\%) & CPA $\left(\sigma^{7}\right)$ & $\mathrm{J}$ \\
\hline JCDS $\left(\sigma^{7}\right)$ & FPDN (우) & $\mathrm{K}$ \\
\hline 02789AGN $\left(\sigma^{x}\right)$ & MDS (ㅇ) & $\mathrm{L}$ \\
\hline
\end{tabular}




\subsection{Evaluation of PM Response}

Disease symptoms caused by natural infection of $P$. xanthii under greenhouse conditions became apparent 60 days after transplantation. When PM disease symptoms were clearly distinguishable, phenotypic scoring of PM resistance was conducted at 2-week intervals until disease symptoms had spread to all parts of the susceptible plants. The plants were considered to be PM-susceptible when the white spores of $P$. xanthii covered more than $10 \%$ of the overall cucumber leaves. Others were considered to be PM resistant. Ten individuals from each cucumber inbred line were used for the evaluation of PM response. Finally, 100 Korean cucumber inbred lines were clearly distinguishable in the PM-resistant and PM-susceptible groups. The PM resistance and PM susceptibility are presented in Figure 1 and Table 2.

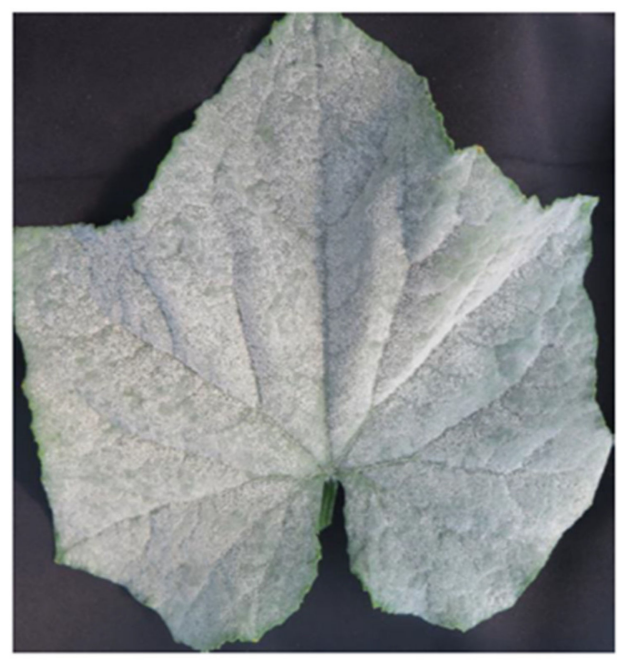

(a)

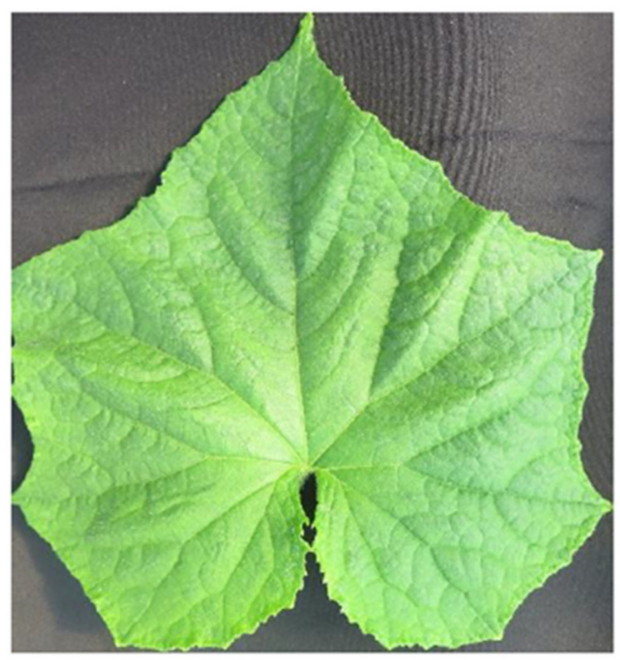

(b)

Figure 1. Typical phenotypic responses of PM infection. (a,b) Represent PM-susceptible and PM resistant phenotypes, respectively.

Table 2. PM phenotypic evaluation and genotyping analysis results of 100 cucumber inbred lines.

\begin{tabular}{|c|c|c|c|c|c|c|c|c|}
\hline $\begin{array}{l}\text { Line } \\
\text { No. }\end{array}$ & Generation $^{a}$ & $\begin{array}{l}\text { Resistance } \\
\text { Source }\end{array}$ & $\begin{array}{l}\text { Phenotypic } \\
\text { Evaluation } \\
\text { (PE) } b\end{array}$ & CsaMLO8 ${ }^{\mathrm{c}}$ & $\begin{array}{c}\text { PE vs. } \\
\text { CsaMLO8 }^{\mathrm{d}}\end{array}$ & CsLRR-RPK2 ${ }^{\mathrm{e}}$ & $\begin{array}{c}\text { PE vs. } \\
C s L R R-R P K 2{ }^{\mathrm{f}}\end{array}$ & $\begin{array}{c}\text { CsaMLO8 vs. } \\
\text { CsLRR-RPK2 } \mathrm{g}\end{array}$ \\
\hline DS 1 & 8 & - & S & S & True & S & True & True \\
\hline DS 2 & 9 & - & $S$ & $\mathrm{~S}$ & True & $S$ & True & True \\
\hline DS 3 & 9 & - & $S$ & $S$ & True & S & True & True \\
\hline DS 4 & 9 & - & $S$ & $\mathrm{~S}$ & True & $S$ & True & True \\
\hline DS 5 & 9 & - & S & $\mathrm{S}$ & True & $S$ & True & True \\
\hline DS 6 & 5 & - & $S$ & $S$ & True & $S$ & True & True \\
\hline DS 7 & 5 & - & S & $\mathrm{S}$ & True & $S$ & True & True \\
\hline DS 8 & 5 & - & $S$ & $S$ & True & $S$ & True & True \\
\hline DS 9 & 5 & - & $S$ & $S$ & True & S & True & True \\
\hline DS 10 & 5 & - & S & S & True & S & True & True \\
\hline DS 11 & 5 & - & $S$ & $\mathrm{~S}$ & True & $S$ & True & True \\
\hline DS 12 & 5 & - & S & S & True & S & True & True \\
\hline DS 13 & 5 & - & $S$ & $\mathrm{~S}$ & True & $S$ & True & True \\
\hline DS 14 & 5 & - & S & S & True & S & True & True \\
\hline DS 15 & 9 & - & $S$ & $\mathrm{~S}$ & True & $S$ & True & True \\
\hline DS 16 & 9 & - & $S$ & $S$ & True & $S$ & True & True \\
\hline DS 17 & 9 & - & S & S & True & S & True & True \\
\hline DS 18 & 9 & - & $S$ & $\mathrm{~S}$ & True & S & True & True \\
\hline DS 19 & 5 & - & S & S & True & S & True & True \\
\hline DS 20 & 5 & - & $S$ & $S$ & True & $S$ & True & True \\
\hline DS 21 & 5 & - & S & S & True & S & True & True \\
\hline DS 22 & 5 & - & $S$ & $S$ & True & $S$ & True & True \\
\hline DS 23 & 5 & - & S & S & True & S & True & True \\
\hline
\end{tabular}


Table 2. Cont.

\begin{tabular}{|c|c|c|c|c|c|c|c|c|}
\hline $\begin{array}{l}\text { Line } \\
\text { No. }\end{array}$ & Generation $^{a}$ & $\begin{array}{l}\text { Resistance } \\
\text { Source }^{h}\end{array}$ & $\begin{array}{l}\text { Phenotypic } \\
\text { Evaluation } \\
\quad(P E)^{b}\end{array}$ & CsaMLO8 ${ }^{c}$ & $\begin{array}{c}\text { PE vs. } \\
\text { CsaMLO8 }\end{array}$ & $C s L R R-R P K 2^{\mathrm{e}}$ & $\begin{array}{c}\text { PE vs. } \\
C s L R R-R P K 2^{\mathrm{f}}\end{array}$ & $\begin{array}{c}\text { CsaMLO8 vs. } \\
\text { CsLRR-RPK2 g }\end{array}$ \\
\hline DS 24 & 5 & - & $S$ & $S$ & True & $S$ & True & True \\
\hline DS 25 & 5 & - & $S$ & $S$ & True & $S$ & True & True \\
\hline DS 26 & 5 & - & $S$ & $S$ & True & $S$ & True & True \\
\hline DS 27 & 7 & - & $S$ & $S$ & True & $S$ & True & True \\
\hline DS 28 & 7 & - & $S$ & $S$ & True & $S$ & True & True \\
\hline DS 29 & 7 & - & $S$ & $S$ & True & $S$ & True & True \\
\hline DS 30 & $\mathrm{P}$ & - & $S$ & $S$ & True & $S$ & True & True \\
\hline DS 31 & 8 & - & $S$ & $S$ & True & $S$ & True & True \\
\hline DS 32 & 8 & - & $S$ & $S$ & True & $S$ & True & True \\
\hline DS 33 & 8 & - & $S$ & $S$ & True & $S$ & True & True \\
\hline DS 34 & 8 & - & $S$ & $S$ & True & $S$ & True & True \\
\hline DS 35 & 9 & - & $S$ & $S$ & True & $S$ & True & True \\
\hline DS 68 & 7 & A & $\mathrm{R}$ & $S$ & False & $\mathrm{R}$ & True & False \\
\hline DS 72 & 6 & B & $\mathrm{R}$ & $\mathrm{R}$ & True & $\mathrm{R}$ & True & True \\
\hline DS 86 & 6 & $\mathrm{C}$ & $\mathrm{R}$ & $\mathrm{R}$ & True & $\mathrm{R}$ & True & True \\
\hline DS 88 & 6 & $\mathrm{C}$ & $\mathrm{R}$ & $\mathrm{R}$ & True & $S$ & False & False \\
\hline DS 92 & 6 & $\mathrm{D}$ & $\mathrm{R}$ & $\mathrm{R}$ & True & $\mathrm{R}$ & True & True \\
\hline DS 101 & 5 & $\mathrm{D}$ & $\mathrm{R}$ & $S$ & False & $\mathrm{R}$ & True & False \\
\hline DS 102 & 5 & $\mathrm{D}$ & $\mathrm{R}$ & $S$ & False & $\mathrm{R}$ & True & False \\
\hline DS 103 & 5 & $\mathrm{D}$ & $\mathrm{R}$ & $S$ & False & $\mathrm{R}$ & True & False \\
\hline DS 106 & 5 & $\mathrm{D}$ & $\mathrm{R}$ & $\mathrm{R}$ & True & $\mathrm{R}$ & True & True \\
\hline DS 111 & 5 & $\mathrm{D}$ & $\mathrm{R}$ & $\mathrm{R}$ & True & $\mathrm{R}$ & True & True \\
\hline DS 112 & 5 & $\mathrm{D}$ & $\mathrm{R}$ & $\mathrm{R}$ & True & $\mathrm{R}$ & True & True \\
\hline DS 114 & 5 & $\mathrm{D}$ & $\mathrm{R}$ & $\mathrm{R}$ & True & $S$ & False & False \\
\hline DS 115 & 5 & $\mathrm{D}$ & $\mathrm{R}$ & $\mathrm{R}$ & True & $\mathrm{R}$ & True & True \\
\hline DS 116 & 5 & $\mathrm{D}$ & $\mathrm{R}$ & $\mathrm{R}$ & True & $\mathrm{R}$ & True & True \\
\hline DS 117 & 5 & $\mathrm{D}$ & $\mathrm{R}$ & $\mathrm{R}$ & True & $\mathrm{R}$ & True & True \\
\hline DS 119 & 5 & $\mathrm{D}$ & $\mathrm{R}$ & $\mathrm{R}$ & True & $\mathrm{R}$ & True & True \\
\hline DS 121 & 5 & $\mathrm{C}$ & $\mathrm{R}$ & $\mathrm{R}$ & True & $S$ & False & False \\
\hline DS 122 & 5 & $\mathrm{C}$ & $\mathrm{R}$ & $\mathrm{R}$ & True & $\mathrm{R}$ & True & True \\
\hline DS 123 & 5 & $\mathrm{D}$ & $\mathrm{R}$ & $\mathrm{R}$ & True & $\mathrm{R}$ & True & True \\
\hline DS 124 & 5 & $\mathrm{H}$ & $\mathrm{R}$ & $\mathrm{R}$ & True & $\mathrm{R}$ & True & True \\
\hline DS 125 & 5 & $\mathrm{H}$ & $\mathrm{R}$ & $\mathrm{R}$ & True & $\mathrm{R}$ & True & True \\
\hline DS 126 & 5 & $\mathrm{H}$ & $\mathrm{R}$ & $\mathrm{R}$ & True & $S$ & False & False \\
\hline DS 128 & 4 & $\mathrm{E}$ & $\mathrm{R}$ & $\mathrm{R}$ & True & $\mathrm{R}$ & True & True \\
\hline DS 129 & 4 & $\mathrm{E}$ & $\mathrm{R}$ & $\mathrm{R}$ & True & $\mathrm{R}$ & True & True \\
\hline DS 130 & 4 & $\mathrm{E}$ & $\mathrm{R}$ & $\mathrm{R}$ & True & $\mathrm{R}$ & True & True \\
\hline DS 131 & 4 & $\mathrm{E}$ & $\mathrm{R}$ & $\mathrm{R}$ & True & $\mathrm{R}$ & True & True \\
\hline DS 133 & 4 & $\mathrm{E}$ & $\mathrm{R}$ & $\mathrm{R}$ & True & $\mathrm{R}$ & True & True \\
\hline DS 195 & 6 & $\mathrm{~F}$ & $\mathrm{R}$ & $S$ & False & $\mathrm{R}$ & True & False \\
\hline DS 196 & 6 & $\mathrm{~F}$ & $\mathrm{R}$ & $S$ & False & $\mathrm{R}$ & True & False \\
\hline DS 197 & 4 & G & $\mathrm{R}$ & $S$ & False & $\mathrm{R}$ & True & False \\
\hline DS 198 & 4 & G & $\mathrm{R}$ & $\mathrm{R}$ & True & $\mathrm{R}$ & True & True \\
\hline DS 200 & 4 & $\mathrm{H}$ & $\mathrm{R}$ & $\mathrm{R}$ & True & $\mathrm{R}$ & True & True \\
\hline DS 201 & 4 & $\mathrm{H}$ & $\mathrm{R}$ & $\mathrm{R}$ & True & $S$ & False & False \\
\hline DS 202 & 4 & $\mathrm{H}$ & $\mathrm{R}$ & $\mathrm{R}$ & True & $S$ & False & False \\
\hline DS 204 & 4 & $\mathrm{H}$ & $\mathrm{R}$ & $\mathrm{R}$ & True & $S$ & False & False \\
\hline DS 205 & 4 & $\mathrm{H}$ & $\mathrm{R}$ & $S$ & False & $\mathrm{R}$ & True & False \\
\hline DS 206 & 4 & $\mathrm{H}$ & $\mathrm{R}$ & $S$ & False & $\mathrm{R}$ & True & False \\
\hline DS 208 & 4 & $\mathrm{H}$ & $\mathrm{R}$ & $\mathrm{R}$ & True & $\mathrm{R}$ & True & True \\
\hline DS 209 & 4 & $\mathrm{H}$ & $\mathrm{R}$ & $S$ & False & $\mathrm{R}$ & True & False \\
\hline DS 211 & 4 & $\mathrm{C}$ & $\mathrm{R}$ & $\mathrm{R}$ & True & $\mathrm{R}$ & True & True \\
\hline DS 212 & 4 & $\mathrm{C}$ & $\mathrm{R}$ & $S$ & False & $\mathrm{R}$ & True & False \\
\hline DS 213 & 4 & $\mathrm{C}$ & $\mathrm{R}$ & $\mathrm{R}$ & True & $\mathrm{R}$ & True & True \\
\hline DS 214 & 4 & $\mathrm{C}$ & $\mathrm{R}$ & $\mathrm{R}$ & True & $\mathrm{R}$ & True & True \\
\hline DS 215 & 4 & $\mathrm{C}$ & $\mathrm{R}$ & $S$ & False & $S$ & False & True \\
\hline$\overline{\mathrm{DS}} 216$ & 4 & $\mathrm{C}$ & $\mathrm{R}$ & $\mathrm{R}$ & True & $\mathrm{R}$ & True & True \\
\hline DS 217 & 4 & $\mathrm{C}$ & $\mathrm{R}$ & $\mathrm{R}$ & True & $S$ & False & False \\
\hline DS 219 & 4 & $\mathrm{C}$ & $\mathrm{R}$ & $S$ & False & $S$ & False & True \\
\hline$\overline{\mathrm{DS}} 221$ & 3 & $\mathrm{I}$ & $\mathrm{R}$ & $\mathrm{R}$ & True & $S$ & False & False \\
\hline DS 223 & 3 & $\mathrm{I}$ & $\mathrm{R}$ & $S$ & False & $S$ & False & True \\
\hline$\overline{\mathrm{DS} 225}$ & 3 & $\mathrm{I}$ & $\mathrm{R}$ & $S$ & False & $S$ & False & True \\
\hline$\overline{\mathrm{DS}} 229$ & 3 & $\mathrm{~J}$ & $\mathrm{R}$ & $S$ & False & $\mathrm{R}$ & True & False \\
\hline DS 234 & 3 & $\mathrm{~J}$ & $\mathrm{R}$ & $S$ & False & $\mathrm{R}$ & True & False \\
\hline DS 235 & 3 & $\mathrm{~J}$ & $\mathrm{R}$ & $S$ & False & $\mathrm{R}$ & True & False \\
\hline DS 241 & 3 & $\mathrm{C}$ & $\mathrm{R}$ & $S$ & False & $S$ & False & True \\
\hline
\end{tabular}


Table 2. Cont.

\begin{tabular}{|c|c|c|c|c|c|c|c|c|}
\hline $\begin{array}{l}\text { Line } \\
\text { No. }\end{array}$ & Generation $^{a}$ & $\begin{array}{l}\text { Resistance } \\
\text { Source }^{h}\end{array}$ & $\begin{array}{l}\text { Phenotypic } \\
\text { Evaluation } \\
\text { (PE) }^{b}\end{array}$ & CsaMLO8 ${ }^{\mathrm{c}}$ & $\begin{array}{c}\text { PE vs. } \\
\text { CsaMLO8 }\end{array}$ & $C s L R R-R P K 2^{\mathrm{e}}$ & $\begin{array}{c}\text { PE vs. } \\
\text { CsLRR-RPK2 }\end{array}$ & $\begin{array}{c}\text { CsaMLO } 8 \text { vs. } \\
\text { CsLRR-RPK } 2 \mathrm{~g}\end{array}$ \\
\hline DS 340 & 9 & K & $\mathrm{R}$ & S & False & $\mathrm{R}$ & True & False \\
\hline DS 341 & 9 & K & $\mathrm{R}$ & $S$ & False & $\mathrm{R}$ & True & False \\
\hline DS 389 & 4 & $\mathrm{~L}$ & $\mathrm{R}$ & $S$ & False & $\mathrm{R}$ & True & False \\
\hline DS 394 & 4 & $\mathrm{~L}$ & $\mathrm{R}$ & $S$ & False & $S$ & False & True \\
\hline$\overline{\text { DS } 396}$ & 4 & $\mathrm{~L}$ & $\mathrm{R}$ & $S$ & False & $\mathrm{R}$ & True & False \\
\hline DS 398 & 4 & $\mathrm{~L}$ & $\mathrm{R}$ & $S$ & False & $\mathrm{R}$ & True & False \\
\hline DS 417 & 3 & M & $S$ & $\mathrm{R}$ & False & $S$ & True & False \\
\hline DS 420 & 3 & $\mathrm{M}$ & S & $\mathrm{R}$ & False & $S$ & True & False \\
\hline DS 424 & 3 & $\mathrm{~L}$ & $\mathrm{R}$ & $S$ & False & $\mathrm{S}$ & False & True \\
\hline$\overline{\text { DS } 425}$ & 3 & $\mathrm{~L}$ & $\mathrm{R}$ & S & False & $\mathrm{R}$ & True & False \\
\hline DS 429 & 3 & M & $S$ & $\mathrm{R}$ & False & $S$ & True & False \\
\hline
\end{tabular}

Note: ${ }^{a}$ Represents the generations of progeny by consecutive crossings of self-pollination $\left(\mathrm{F}_{3}\right.$ to $\mathrm{F}_{9}$ generations and pure line $(\mathrm{P})$, respectively). ${ }^{b}$ Represents the degree of PM disease symptoms. ${ }^{c}$ and ${ }^{\mathrm{e}}$ represent the genotyping analysis results using the CsaMLO8-InDel and CSLRR-RPK2-CAPS markers, respectively. ${ }^{\mathrm{d}}$ and ${ }^{\mathrm{f}}$ show the consistency between the phenotypic and genotyping analysis results. True and False represent the consistency and inconsistency between the phenotypic evaluation and genotyping analysis results, respectively. $\mathrm{g}$ True or False represents the consistency and inconsistency between the two genotyping analysis results. Underlined and bold represent the seven PM-resistant inbred lines, which did not originate from introgression of either CsaMLO8 or CsLRR-RPK2 alleles. ${ }^{\mathrm{h}}$ Represents the original sources of the PM resistance. The same character indicates that the same PM-resistant germplasm was used as the PM-resistant donor for the breeding of inbred lines. The PM resistance sources A, B, C, D, E, F, G, H, I, J, K, and L are shown in Table 1.

\subsection{Genomic DNA Isolation and Molecular Marker Design}

Fresh young leaves of 100 Korean cucumber germplasms were used to isolate genomic DNA (gDNA). The DNeasy Plant Mini Kit (Qiagen, Hilden, Germany) was used to isolate gDNA. The quality and quantity of the gDNAs were calculated using a Nanodrop ND-2000 spectrophotometer, following the manufacturer's instructions (Thermo Fisher Scientific, Waltham, MA, USA). Geneious Pro 9.1.8 (Biomatters, Auckland, New Zealand) was used to (I) design InDel and cleave amplified polymorphic sequences (CAPS) markers for CsaMLO8 and CsLRR-RPK2, respectively; and (II) identify appropriate restriction enzymes and restriction sites for the CsLRR-RPK2 gene. HinfI enzyme (New England BioLabs, Ipswich, MA, USA) was selected and used as a restriction enzyme for the CsLRR-RPK2CAPS marker. The sequences of primers for both markers are shown in Table 3, while the gene organization is presented in Figure 2. In this study, Gy14 (version 2.0) and Chinese Long (version 2.0) genome sequences were used as the cucumber reference sequences.

Table 3. Information on CsLRR-RPK2-CAPS and CsaMLO8-InDel markers.

\begin{tabular}{|c|c|c|c|c|}
\hline Name of Gene & Marker Types & Restriction Enzyme & Forward Sequence $\left(5^{\prime}\right.$ to $\left.3^{\prime}\right)$ & Reverse Sequence $\left(5^{\prime}\right.$ to $\left.3^{\prime}\right)$ \\
\hline CsLRR-RPK2 & CAPS & HinfI & GCAACAAGTTCAATGGACCAC & GAATCTCTCCAGTCAAATTGTTTCC \\
\hline CsaMLO8 & InDel & - & TATGGCTGCCTTTCATCTCCT & TCCAAGCAAAGAAGGCAAGC \\
\hline
\end{tabular}
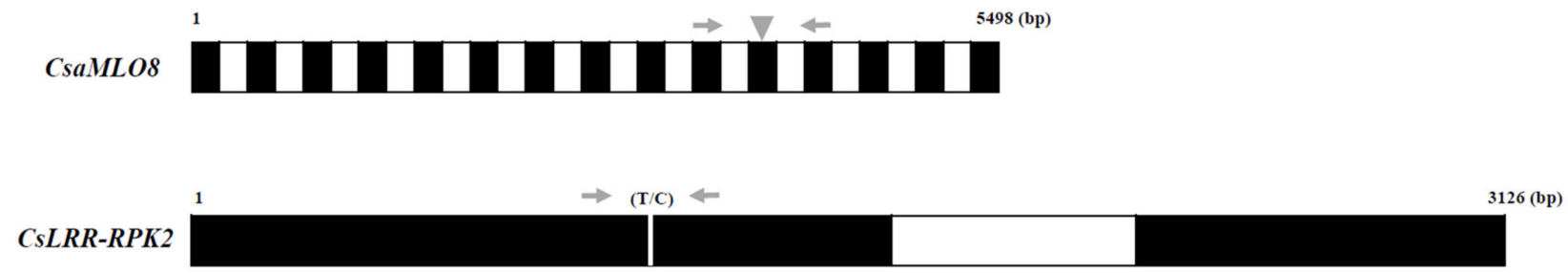

Figure 2. Schematic structure of two PM resistance alleles (CsLRR-RPK2 and CsaMLO8). Exon-intron structures of CsaMLO8 and CSLRR-RPK2 genes are represented by black and white boxes, respectively. The gray arrows represent the forward and reverse primers of CsaMLO8-InDel and CsLRR-RPK2-CAPS markers, respectively. The gray triangle in the 11 leventh exon of CsaMLO8 represents the position of $1449 \mathrm{bp}$ insertion. The white bar in the 1 first exon of CsLRR-RPK2 represents the SNP (T/C). The digits, 1-5498 and 1-3126 represent the genomic DNA length of CsaMLO8 and CsLRR-RPK2, respectively. 


\subsection{Genotyping of Cucumber Inbred Lines}

For the genotyping of CsaMLO8 and CsLRR-RPK2 alleles, we developed InDel and CAPS markers, respectively. CsaMLO8-InDel markers were composed of a combination of a forward primer (5'-TATGGCTGCCTTTCATCTCCT- $\left.3^{\prime}\right)$ and reverse primer $\left(5^{\prime}-\right.$ TCCAAGCAAAGAAGGCAAGC-3'). DNA samples were amplified using CsaMLO8InDel markers and followed by a polymerase chain reaction (PCR) reaction program: $94{ }^{\circ} \mathrm{C}$ for $5 \mathrm{~min}, 30$ cycles of $94{ }^{\circ} \mathrm{C}$ for $20 \mathrm{~s}, 65{ }^{\circ} \mathrm{C}$ for $20 \mathrm{~s}$, and $72{ }^{\circ} \mathrm{C}$ for $90 \mathrm{~s}$, with a final cycle at $72{ }^{\circ} \mathrm{C}$ for $5 \mathrm{~min}$. CsLRR-RPK2-CAPS markers were composed of a combination of forward primer ( $5^{\prime}$-GCAACAAGTTCAATGGACCAC- $\left.3^{\prime}\right)$ and reverse primer (5'-GAATCTCTCCAGTCAAATTGTTTCC-3'). DNA samples were amplified using CsLRRRPK2-CAPS markers and the PCR program was as follows: $94{ }^{\circ} \mathrm{C}$ for $5 \mathrm{~min}, 35$ cycles of $94{ }^{\circ} \mathrm{C}$ for $20 \mathrm{~s}, 60^{\circ} \mathrm{C}$ for $10 \mathrm{~s}$, and $72{ }^{\circ} \mathrm{C}$ for $20 \mathrm{~s}$, with a final cycle at $72{ }^{\circ} \mathrm{C}$ for $5 \mathrm{~min}$. For the PCR, Maxime PCR PreMix (iNtRON Biotechnology, Seoul, Korea) was used. PCR amplifications were performed in a Bio-Rad T100 ${ }^{\mathrm{TM}}$ thermocycler (BioRad, CA, USA). HinfI, a restriction enzyme, was added to the PCR amplicons and incubated for 1 hour at $37^{\circ} \mathrm{C}$. The final reaction products were run on a $2 \%$ agarose gel with $0.5 \times$ Tris-borate-EDTA (TBE) buffer and visualized by staining with RedSafe (iNtRON Biotechnology, Seoul, Korea).

\section{Results and Discussion}

The evaluation of PM resistance and genotyping analysis using the markers for CsaMLO8 and CsLRR-RPK2 alleles in 100 Korean cucumber inbred lines is shown in Table 2 and Figure 3. Of the 100 cucumber inbred lines, 62 had a PM-resistant phenotype. In contrast, 38 inbred lines had a PM-susceptible phenotype. The two PM resistance candidate genes used in this study were CsaMLO8 (Csa5G623470) and CsLRR-RPK2 (CsGy5G015660). The CsLRR-RPK2-CAPS marker amplified the flanking region of the SNP (T/C) (Figures 2 and 3a). The SNP of the PM-susceptible line produced double bands (224 bp and $100 \mathrm{bp}$ ) after HinfI digestion, whereas the PM-resistant line showed an absence of restriction sites in the amplicon (Figure 3b). The CsLRR-RPK2-CAPS marker was successfully applied to detect the PM-resistant and PM-susceptible alleles using the ten phenotypically identified (five PM-resistant and five PM-susceptible lines) inbred lines (Figure 3c). The CsaMLO8-InDel marker detected $1449 \mathrm{bp}$ insertion in PM-resistant lines (Figures 2 and 3d). Ten phenotypically identified inbred lines, consisting of five PMresistant and five PM-susceptible lines, were also verified for the successful application of CsaMLO8-InDel (Figure 3d).

To compare the involvement of CsaMLO8 and CsLRR-RPK2 alleles in the PM-resistant phenotype, we applied CsaMLO8-InDel and CsLRR-RPK2-CAPS markers on 100 inbred lines. Genotyping analysis using the CsaMLO8-InDel marker revealed that 30 inbred lines were inconsistent with the phenotypic evaluation results (Table 2). In particular, most of the inconsistency was observed in PM-resistant lines; 44\% (27/62) of PM-resistant inbred lines had PM-susceptible CsaMLO8 alleles. Only 11\% (3/28) of the PM-susceptible inbred lines (DS 417, DS 420, and DS 429) had the PM-resistant CsaMLO8 allele. However, genotyping analysis using the CsLRR-RPK2-CAPS marker revealed fewer inconsistent results. In detail, 16 inbred lines showed inconsistency between CSLRR-RPK2-based genotyping and phenotypic evaluation results. Interestingly, all of the inconsistent results were obtained from the PM-resistant inbred lines. This indicates that analysis of the CsLRR-RPK2 allele is useful for the elimination of PM-susceptible lines during PM resistance breeding programs. More interestingly, the seven PM-resistant inbred lines (DS 215, DS 219, DS 223, DS 225, DS 241, DS 394, and DS 424) based on phenotypic evaluation showed none of the PM resistance alleles of CsaMLO8 and CsLRR-RPK2. This indicates that the PM resistance of these seven inbred lines did not originate from CsaMLO8 or CsLRR-RPK2, but originated from different PM resistance sources. Further studies should be conducted, using these PM-resistant inbred lines, to identify PM-resistant QTL(s) and/or PM-resistant gene(s) to reveal the origin of a new PM-resistant source(s). 
(a)

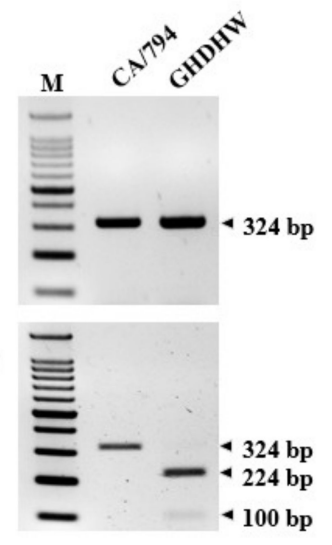

(c)
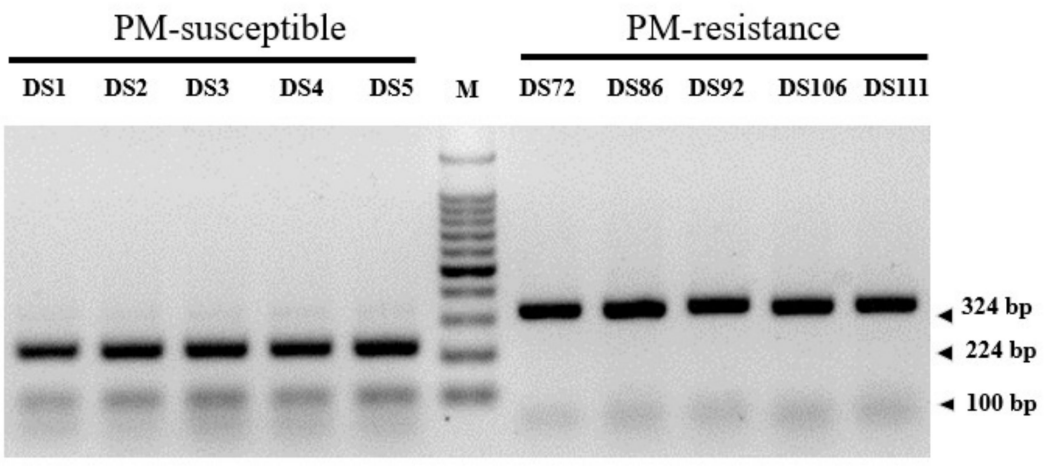

PM-susceptible PM-resistance

(d)

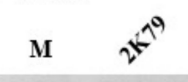

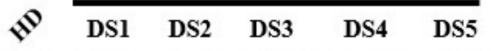

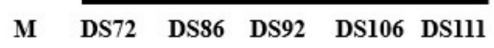

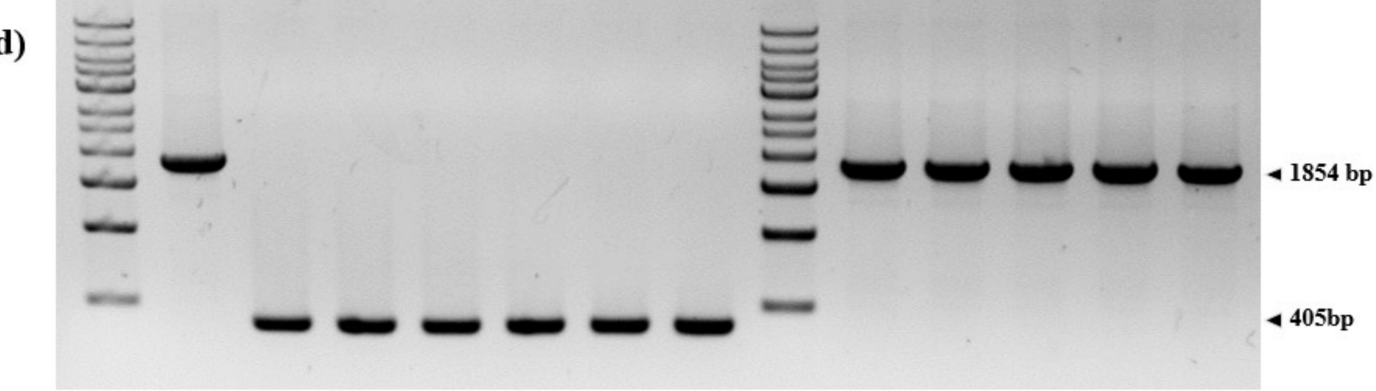

Figure 3. Genotyping analysis of parental and inbred lines using CsLRR-RPK2-CAPS and CsaMLO8-InDel markers. (a) represents the bands amplified by CSLRR-RPK2-CAPS primers. (b) Represents the band patterns after application of HinfI enzyme. (c) Represents the application of CSLRR-RPK2-CAPS marker to the 10 inbred lines (5 PM-resistance and 5 PM-susceptible inbred lines). (d) Represents the bands of parental lines amplified by CsaMLO8-InDel primers and application to the 10 inbred lines (5 PM-resistant and 5 PM-susceptible inbred lines). M, CA794, 2K79, GHDHW, and HD represent the molecular markers (100 bp and $1 \mathrm{~kb}$ ), PM resistant (CA/794 and 2K79), and PM-susceptible (GHDHW and HD) parental lines, respectively. DS1, DS2, DS3, DS4, DS5 and DS72, DS86, DS92, DS106, and DS111 represent the inbred lines of PM-susceptible and PM-resistant lines, respectively. The digits next to the black arrows represent the size of the PCR band.

Furthermore, we classified the sources of PM resistance used in this study (Tables 1 and 2). We detected three different types of PM resistant sources from 12 PM-resistant germplasms used for the generation of 62 PM resistance inbred lines. Firstly, a PM resistance source originated from the CsLRR-RPK2 gene, represented as A, J, and K (Table 2; Supplementary Figure S1). Secondly, a PM resistance source originated from both the CsLRR-RPK2 and CsaMLO8 genes, represented as B, D, E, F, G, and H (Table 2; Supplementary Figure S1). Thirdly, a PM resistance source originated from an unidentified PM resistance source and also contained both resistance genes (CsLRR-RPK2 and CsaMLO8), represented as C, I, and $\mathrm{L}$ (Table 1). These results reveal that divergent sources (at least 1-3 PM-resistant genes were introduced) of PM resistance have been introduced in PM-resistant cucumber breeding programs in Korea. Further extensive study and comparison of phenotypic evaluation and genotyping analysis using increased numbers of PM-resistant sources and their progenies should be conducted, because a limited number of PM-resistant sources and progenies were used in this study.

Comparison of genotyping analysis results between CsaMLO8 and CsLRR-RPK2 showed 32\% (32 inbred lines) inconsistency (Table 1). The three PM-susceptible lines (417, 420, and 429) showed PM-resistant CsaMLO8 alleles, but not PM-resistant CsLRR-RPK2 alleles. Twenty-nine PM-resistant inbred lines showed either PM-susceptible alleles of CsaMLO8 (21 lines) or CSLRR-RPK2 (8 lines). This indicates that PM resistance could be acquired by the introgression of either one of the alleles of CsaMLO8 and/or CsLRR$R P K 2$. Although current phenotypic evaluation analysis results did not strongly support 
the additive effect of both alleles of CsaMLO8 and CsLRR-RPK2 on the number of PM resistance, we observed a moderate correlation between the degree of PM-resistant alleles and the PM-resistant phenotype (data not shown). This fact should be verified by further extensive phenotypic evaluation of divergent PM-resistant inbred lines.

When we compared the allele types of CsaMLO8 and CsLRR-RPK2, 68 inbred lines showed alleles of both PM resistance and PM susceptibility. However, 32 inbred lines showed different allele types between CsaMLO8 and CsLRR-RPK2. This fact can be explained in different ways. Considering the high proportion (more than two-fold) of the same alleles of CsaMLO8 and CsLRR-RPK2, it may be thought that both alleles could easily co-migrate during meiosis. However, both genes (CsLRR-RPK2 and CsaMLO8) are located $8.8 \mathrm{Mb}$ apart on Chromosome 5. When we consider the genetic recombination (bin) of Chromosome 5 as $0.37 \mathrm{cM}$, equivalent to $228 \mathrm{~kb}$ [29], it is unlikely to co-migrate during meiosis. In addition, it has been proposed that three segregation distorted regions (SDR) could exist on Chromosome1, 4, and 6 [29]. The SDRs also cannot explain the co-migration of both allele pairs, because the Chromosome 5 is not likely to contain SDRs. Considering the fact that most inconsistencies were observed before the $\mathrm{F}_{4}$ generation, each allele of CsLRR-RPK2 and CsaMLO8 probably followed independent meiotic recombination events. Race identification of PM has been well identified in melons [30-36]. For example, 12 races of PM (race 1, 2, 3, 4, 5, 6, 7, N3, N4, A, O, and S) have recently been identified in melons [33]. However, race identification of PM in cucumbers has not been well identified. In Korea, Race 1 of PM has been proposed to be dominant. Therefore, we do not have a detailed population structure of the races of PM in cucumbers. This suggests that each allele of CsLRR-RPK2 and CsaMLO8 may be responsible for different races of PM in cucumbers. Breeders should continuously select the cucumber plants that show strong resistance to PM. Therefore, consecutive selections of PM-resistant lines were followed after self-pollination. The consecutive selection of PM-resistant lines from generation to generation may accumulate PM-resistant allele pairs (CsaMLO8 and CsLRR-RPK2) in PM-resistant lines. This could be a more plausible explanation than the co-migration of both allele pairs during meiotic division.

\section{Conclusions}

In this study, we applied PM-resistant molecular markers derived from two PMresistant candidate genes (CsaMLO8 and CsLRR-RPK2) to 100 Korean inbred lines to evaluate the accuracy of marker-assisted selection and to understand the origin of PM resistance in breeding inbred lines in Korea. Our results provided reliable evidence that confirms two PM-resistant candidate genes and efficiently utilized these genes for the detection of PM-resistant resources and inbred lines. Furthermore, the CsLRR-RPK2-CAPS marker in comparison to the CsaMLO8-InDel marker showed a strong correlation with the PM-resistant phenotype. In addition, our results revealed that unidentified PM-resistant sources used in breeding programs in Korea are not related to either PM-resistant candidate gene (CsaMLO8 and CsLRR-RPK2).

Supplementary Materials: The following are available online at https://www.mdpi.com/article/10 .3390/agronomy11112191/s1, Figure S1: CsLRR-RPK2-CAPS and CsaMLO8-InDel markers-based genotyping analysis results.

Author Contributions: I.B. and S.L. designed the research. M.B.A. and I.B. performed the majority of the research. M.B.A., I.B. and S.L. analyzed and commented on the results. M.B.A. and S.L. combined the results and wrote the paper. All authors have read and agreed to the published version of the manuscript.

Funding: This work was supported under the basic science research program (NRF 2020R1A2C108800) funded by the National Research Foundation of Korea.

Data Availability Statement: The data shown in this paper are available from the corresponding author by request. 
Acknowledgments: We thank all the persons of DONGOH SEED who managed the cucumber cultivation field.

Conflicts of Interest: Author Ikhyun Bae is employed by DONGOH SEED. The rest of the authors declare that the research was conducted in the absence of any commercial or financial relationships.

\section{References}

1. Liu, L.Z.; Yuan, X.J.; Cai, R.; Pan, J.S.; He, H.L.; Yuan, L.H.; Guan, Y.; Zhu, L.H. Quantitative trait loci for resistance to powdery mildew in cucumber under seedling spray inoculation and leaf disc infection. J. Phytopathol. 2008, 156, 691-697.

2. Huang, S.; Li, R.; Zhang, Z.; Li, L.; Gu, X.; Fan, W. The genome of the cucumber, Cucumis sativus L. Nat. Genet. 2009, 41, $1275-1281$. [CrossRef] [PubMed]

3. Bardin, M.; Carlier, J.; Nicot, P.C. Genetic differentiation in the French population of Erysiphe cichoracearum, a causal agent of powdery mildew of cucurbits. Plant Pathol. 1999, 48, 531-540. [CrossRef]

4. Bertrand, F. Powdery Mildews of Cucurbits: Pure Culture, Variability and Study of Susceptibility in the Muskmelon Species. Ph.D. Thesis, University of Paris XI, Orsay, France, 1991.

5. Del-Pino, D.; Olalla, L.; Pérez-García, A.; Rivera, M.E.; García, S.; Moreno, R. Occurrence of races and pathotypes of cucurbit powdery mildew in southeastern Spain. Phytoparasitica 2002, 30, 459-466. [CrossRef]

6. He, X.M.; Li, Y.H.; Pandey, S.; Yandell, B.S.; Pathak, M.; Weng, Y. QTL mapping of powdery mildew resistance in WI 2757 cucumber (Cucumis sativus L.). Theor. Appl. Genet. 2013, 126, 2149-2161. [CrossRef]

7. Hosoya, K.; Narisawa, K.; Pitrat, M.; Ezura, H. Race identification in powdery mildew (Sphaerotheca fuliginea) on melon (Cucumis melo) in Japan. Plant Breed. 1999, 118, 259-262. [CrossRef]

8. Kooistra, E. Powdery mildew resistance in cucumber. Euphytica 1968, 17, 236-244. [CrossRef]

9. Lee, J.H.; Jang, K.S.; Lee, W.J.; Choi, Y.H. Resistance of cucurbits to Podosphaera xanthii Race 1. Korean J. Hortic. Sci. Technol. 2014, 673-683. [CrossRef]

10. Pérez-García, A.; Romero, D.; Fernández-Ortuño, D.; López-Ruiz, F.; De Vicente, A.; Tores, J.A. The powdery mildew fungus Podosphaera fusca (synonym Podosphaera xanthii), a constant threat to cucurbits. Mol. Plant Pathol. 2009, 10, 153-160. [CrossRef]

11. Vakalounakis, D.J.; Klironomou, E.; Papadakis, A. Species spectrum, host range and distribution of powdery mildews on Cucurbitaceae in Crete. Plant Pathol. 1994, 43, 813-818. [CrossRef]

12. Vakalounakis, D.J.; Klironomou, E. Race and mating type identification of powdery mildew on cucurbits in Greece. Plant Pathol. 1995, 44, 1033-1038. [CrossRef]

13. Hollomon, D.W.; Wheeler, I.E. Controlling powdery mildews with chemistry. In The Powdery Mildews. A Comprehensive Treatise; Bélanger, R.R., Bushnell, W.R., Dik, A.J., Carver, T.L.W., Eds.; APS Press: Saint Paul, MN, USA, 2002; pp. $249-255$.

14. Innark, P.; Ratanachan, T.; Khanobdee, C.; Samipak, S.; Jantasuriyarat, C. Downy mildew resistant/susceptible cucumber germplasm (Cucumis sativus L.) genetic diversity assessment using ISSR markers. Crop Prot. 2014, 60, 56-61. [CrossRef]

15. McGrath, M.T. Fungicide Resistance in Cucurbit Powdery Mildew: Experiences and Challenges. Plant Dis. 2001, 85, 236-245. [CrossRef] [PubMed]

16. Nie, J.; He, H.; Peng, J.; Yang, X.; Bie, B.; Zhao, J.; Wang, Y.; Si, L.; Pan, J.S.; Cai, R. Identification and fine mapping of pm5.1: A recessive gene for powdery mildew resistance in cucumber (Cucumis sativus L.). Mol. Breed. 2015, 35, 7. [CrossRef]

17. Nie, J.; Wang, Y.; He, H.; Guo, C.; Zhu, W.; Pan, J.; Li, D.; Lian, H.; Pan, J.; Cai, R. Loss-of-Function Mutations in CsMLO1 Confer Durable Powdery Mildew Resistance in Cucumber (Cucumis sativus L.). Front. Plant Sci. 2015, 6, 1155. [CrossRef]

18. Schroeder, W.T.; Provvidenti, R. Resistance to benomyl in powdery mildew of cucurbits. Plant Dis. Rep. 1969, 53, $271-275$.

19. Fukino, N.; Yoshioka, Y.; Sugiyama, M.; Sakata, Y.; Matsumoto, S. Identification and validation of powdery mildew (Podosphaera xanthii)-resistant loci in recombinant inbred lines of cucumber (Cucumis sativus L.). Mol. Breed. 2013, 32, 267-277. [CrossRef]

20. De Ruiter, W.; Hofstede, R.; de Vries, J.; van den Heuvel, H. Combining QTL for resistance to CYSDV and powdery mildew in a single cucumber line. In Proceedings of the 9th EUCARPIA Meeting on Genetics and Breeding of Cucurbitaceae, Avignon, France, 21-24 May 2008; Pitrat, M., Ed.; INRA: Avignon, France, 2008.

21. Sakata, Y.; Kubo, N.; Morishita, M.; Kitadani, E.; Sugiyama, M.; Hirai, M. QTL analysis of powdery mildew resistance in cucumber. Theor. Appl. Genet. 2006, 112, 243-250. [CrossRef] [PubMed]

22. Wang, Y.; VandenLangenberg, K.; Wen, C.; Wehner, T.C.; Weng, Y.Q. QTL mapping of downy and powdery mildew resistances in PI 197088 cucumber with genotyping-by-sequencing in RIL population. Theor. Appl. Genet. 2018, 131, 597-611. [CrossRef]

23. Zhang, S.P.; Liu, M.M.; Miao, H.; Zhang, S.Q.; Yang, Y.H.; Xie, B.Y.; Gu, X.F. QTL mapping of resistance genes to powdery mildew in cucumber (Cucumis sativus L.). Sci. Agric. Sin. 2011, 44, 3584-3593.

24. Xu, X.; Yu, T.; Xu, R.; Shi, Y.; Lin, X.; Xu, Q.; Qi, X.; Weng, Y.; Chen, X. Fine mapping of a dominantly inherited powdery mildew resistance major-effect QTL, Pm1.1, in cucumber identifies a $41.1 \mathrm{~kb}$ region containing two tandemly arrayed cysteine-rich receptor-like protein kinase genes. Theor. Appl. Genet. 2016, 129, 507-516. [CrossRef] [PubMed]

25. Zhang, K.; Wang, X.; Zhu, W.; Qin, X.; Xu, J.; Cheng, C.; Lou, Q.; Li, J.; Chen, J. Complete resistance to powdery mildew and partial resistance to downy mildew in a Cucumis hystrix introgression line of cucumber were controlled by a co-localized locus. Theor. Appl. Genet. 2018, 131, 2229-2243. [CrossRef] [PubMed]

26. Berg, J.A.; Appiano, M.; Bijsterbosch, G.; Visser, R.G.F.; Schouten, H.J.; Bai, Y. Functional characterization of cucumber (Cucumis sativus L.) Clade V MLO genes. BMC Plant Biol. 2017, 17, 80. [CrossRef] 
27. Berg, J.A.; Appiano, M.; Santillan-Martinez, M.; Hermans, F.W.; Vriezen, W.H.; Visser, R.G.; Bai, Y.; Schouten, H.J. A transposable element insertion in the susceptibility gene CsaMLO8 results in hypocotyl resistance to powdery mildew in cucumber. BMC Plant Biol. 2015, 15, 243. [CrossRef]

28. Zhang, C.; Badri Anarjan, M.; Win, K.T.; Begum, S.; Lee, S. QTL-seq analysis of powdery mildew resistance in a Korean cucumber inbred line. Theor. Appl. Genet. 2021, 134, 435-451. [CrossRef] [PubMed]

29. Ren, Y.; Zhang, Z.; Liu, J.; Staub, J.E.; Han, Y. An Integrated Genetic and Cytogenetic Map of the Cucumber Genome. PLoS ONE 2009, 4, e5795. [CrossRef]

30. Izumikawa, Y.; Kuzuya, M.; Takazusu, Y.; Miyagi, M. Occurrence of several pathogenic strains of melon powdery mildew with different host-specificity and search for melon breeding materials resistant to these strains. In Proceedings of the 114th Meeting of the Japanese Society of Breeding, Shiga, Japan, 11-12 October 2008.

31. Jagger, I.C.; Whitaker, T.W.; Porter, D.R. A new biologic form of powdery mildew on muskmelons in the Imperial Valley of California. Plant Dis. Rep. 1938, 22, 275-276.

32. Kenigsbuch, D.; Cohen, Y. Inheritance and allelism of genes for resistance to races 1 and 2 of Sphaerotheca fuliginea in muskmelon. Plant Dis. 1992, 76, 626-629. [CrossRef]

33. Kim, H.; Park, J.; Noi, I. Identification of fungal races that cause powdery mildew in melon (Cucumis melo L.) and selection of resistant commercial melon cultivars against the identified races in Korea. J. Plant Biotechnol. 2016, 43, 58-65. [CrossRef]

34. Kuzuya, M.; Yashiro, K.; Tomita, K. Melon breeding for resistance to powdery mildew in respect to its races. Proc. Veg. Tea Sci. 2004, 1, 39-43.

35. Pitrat, M.; Dogimont, C.; Bardin, M. Resistance to fungal diseases of foliage in melon. In Cucurbitaceae '98 Evaluation and Enhancement of Cucurbit Germplasm; McCreight, J.D., Ed.; ASHS Press: Alexandria, VA, USA, 1998; pp. 167-173.

36. Pryor, D.E.; Whitaker, T.W.; Davis, G.N. The development of powdery mildew resistant cantaloupes. Proc. Am. Soc. Hortic. Sci. 1946, 47, 347-356. 